\title{
A chemical strategy toward novel brain-penetrant EZH2 inhibitors
}

Authors: Rui Liang ${ }^{1, *}$, Daisuke Tomita ${ }^{1}$, Yusuke Sasaki ${ }^{1}$, John Ginn ${ }^{1}$, Mayako Michino ${ }^{1}$, David J. Huggins ${ }^{1,2}$, Leigh Baxt ${ }^{1}$, Stacia Kargman ${ }^{1}$, Maaz Shahid ${ }^{6-8}$, Kazuyoshi Aso ${ }^{1}$, Mark Duggan ${ }^{3}$, Andrew W. Stamford ${ }^{1}$, Elisa DeStanchina ${ }^{4}$, Nigel Liverton ${ }^{1}$, Peter T. Meinke ${ }^{1,5}$, Michael A. Foley ${ }^{1}$, Richard E. Phillips ${ }^{6-8, *}$

Affiliations:

${ }^{1}$ Tri-Institutional Therapeutics Discovery Institute, 413 East 69th Street, New York, NY, 10021, USA.

${ }^{2}$ Department of Physiology and Biophysics, Weill Cornell Medical College, New York, NY 10021, USA

${ }^{3}$ LifeSci Consulting, LLC. 18243 SE Ridgeview Drive, Tequesta, FL 33469, USA

${ }^{4}$ Molecular Pharmacology Program, Memorial Sloan Kettering Cancer Center, New York, NY 10065, USA

${ }^{5}$ Department of Pharmacology, Weill Cornell Medical College, New York, NY 10021, USA.

${ }^{6}$ Department of Neurology, Perelman School of Medicine, University of Pennsylvania, Philadelphia, PA 19104, USA

${ }^{7}$ Epigenetics Program, Perelman School of Medicine, Philadelphia, PA 19104, USA

${ }^{8}$ Abramson Cancer Center, Perelman School of Medicine, Philadelphia, PA 19104, USA

*Corresponding author. Email: richard.phillips@pennmedicine.upenn.edu, rliang@tritdi.org

\begin{abstract}
Aberrant gene-silencing through dysregulation of polycomb protein activity has emerged as an important oncogenic mechanism in cancer, implicating polycomb proteins as important therapeutic targets. Recently, an inhibitor targeting $\mathrm{EZH} 2$, the methyltransferase component of PRC2, received FDA approval following promising clinical responses in cancer patients. However, the current array of EZH2 inhibitors have poor brain-penetrance limiting their use in patients with CNS malignancies, a number of which have been shown to be sensitive to EZH2 inhibition. To address this need, we have identified a chemical strategy, based on computational modeling of pyridone-containing EZH2 inhibitor scaffolds, to minimize P-glycoprotein activity and here we report the first brain-penetrant EZH2 inhibitor, TDI-6118 (compound 5).
\end{abstract}


Additionally, in the course of our attempts to optimize this compound we discovered TDI-11904 (compound 21); a novel, highly-potent, and peripherally active EZH2 inhibitor based on a 7 member ring structure.

\section{Introduction}

The characterization of somatic genomes in cancer through efforts such as TCGA (The Cancer Genome Atlas), ${ }^{1}$ has shown chromatin factors are highly mutated in cancer, with up to $40 \%$ of cancers bearing at least one mutation in an epigenetic regulator. ${ }^{2}$ This work has generated much interest in targeting epigenetic regulators therapeutically in cancer. One of the most well-characterized epigenetic regulators is EZH2 (enhancer of zeste homologue 2), the methyltransferase ('writer') component of the polycomb repressive complex 2 (PRC2). ${ }^{3} \mathrm{EZH} 2$ catalyzes the generation of histone-3 lysine 27 methylation (H3K27me), ${ }^{4}$ an epigenetic mark which is critical for mediating gene repression in many contexts including development. ${ }^{5} \mathrm{~A}$ wealth of studies have implicated an oncogenic function for $\mathrm{EZH} 2$ through its ability to repress tumor suppressor genes ${ }^{6}$ stimulating many EZH2 drug discovery programs. ${ }^{7,8,9}$ For example, certain cancers such as lymphoma harbor recurrent gain-of-function mutations in EZH2, leading to aberrant gene repression through enhanced production of H3K27 trimethylation (H3K27me3). ${ }^{10,11}$ Additionally, tumors which bear mutations in the SWISNF (SWItch/Sucrose Non-Fermentable) complex including sarcomas are frequently sensitive to $E Z H 2$ inhibition, ${ }^{12,13,14}$ due to an evolutionary conserved synthetic lethal relationship between SWI-SNF and polycomb. ${ }^{15,16}$

Validation of EZH2 as a bona fide therapeutic target in cancer was recently achieved with encouraging clinical responses to tazemetostat in patient trials leading to FDA approval in epithelioid sarcoma and follicular lymphoma. ${ }^{17,18}$ Although this and other drug discovery programs have been effective in generating EZH2 inhibitors for human clinical trials, there remains a need for novel chemical matter to address other specific contexts in oncology and beyond. One important area of unmet need is CNS malignancies. ${ }^{19}$ Twenty percent of all patients with cancer will develop brain metastases $^{20,21}$ and several of the cancer-types which have a propensity to metastasize to the brain have been shown to be effectively treated with $\mathrm{EZH} 2$ inhibition in pre-clinical cancer models, including small cell lung cancer, ${ }^{22}$ specific breast adenocarcinoma subtypes $^{23}$ and melanoma. ${ }^{24,25}$ Furthermore, malignant brain tumors are the leading cause of cancer-related mortality in children. ${ }^{26}$ Notably, several pediatric brain tumors are characterized by a reprogrammed epigenomic landscape in which EZH2 is essential for tumor maintenance including midline glioma, ${ }^{27,28}$ ependymoma ${ }^{29}$ and atypical rhabdoid tumors of the brain ${ }^{30,31}$ all of which lack effective therapies. Thus, a brainpenetrant EZH2 inhibitor could be of great utility in oncology. 

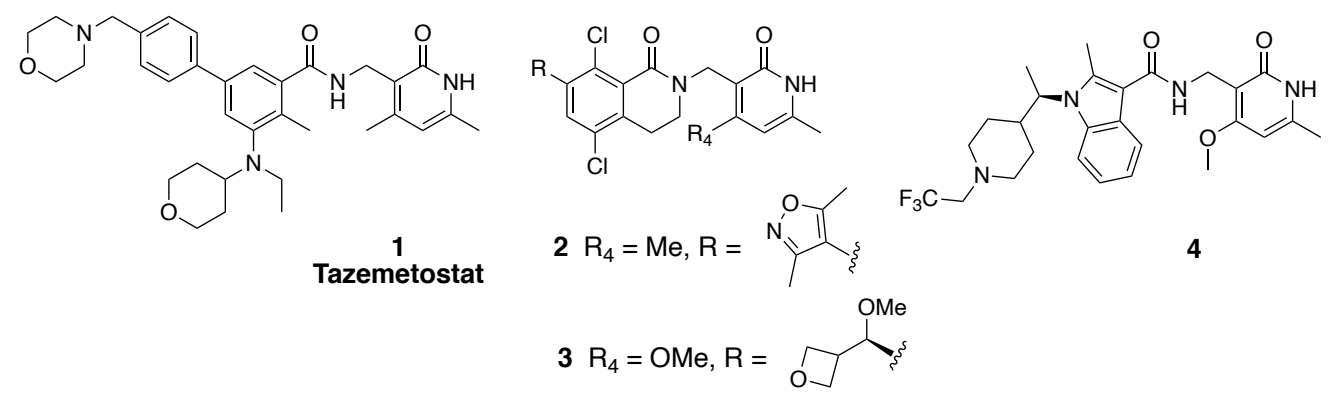

Figure 1. EZH2 inhibitors reported in the literature.

Many successful case studies have been reported in the literature where brain penetration is enhanced by minimizing $\mathrm{P}$-glycoprotein ( $\mathrm{P}$-gp) efflux transport and increasing passive permeability. ${ }^{32}$ Hydrogen bond donor count is one key physicochemical property which influences P-gp substrate activity, ${ }^{33,34}$ and reducing the number of hydrogen bond donors has been shown as an effective strategy to lower efflux transport. ${ }^{35,36,37,38}$ While EZH2 inhibitors reported in the literature possess an overall broad diversity of structures, most share a common, conserved pyridone which is critical for engaging and inhibiting $\mathrm{EZH} 2$ enzymatic activity [Tazemetostat (1), ${ }^{7} \mathrm{PF}$ 06726304 (2), ${ }^{39}$ PF-06821497 (3), ${ }^{40} \mathrm{CPI}-1205$ (4), ${ }^{41}$ (Fig. 1)]. It has been shown that pyridone containing EZH2 inhibitors are substrates of efflux transporters which severely restrict their distribution into the brain. ${ }^{42}$ We hypothesized that the common pyridone motif represents a good substrate for efflux transporters due to the presence of a hydrogen bond donor $\mathrm{NH}$ group. We envisioned that masking the hydrogen bond donor $\mathrm{NH}$ group in the pyridone could produce compounds that maintain a favorable potency profile and possess a reduced efflux ratio leading to small molecule inhibitors with improved brain penetration properties.

\section{Results and Discussion}

We initiated our medicinal chemistry campaign with an analysis of the crystal structure of Polycomb repressive complex 2 (PRC2) bound to a pyridone-containing inhibitor (PDB:5IJ7). ${ }^{43}$ The pyridone moiety forms two hydrogen-bond interactions with the backbone of Trp624 from the conserved GXG motif of the SET domain and a watermediated interaction with the sidechain of Asn688. Calculation of hydration site thermodynamics using WaterMap ${ }^{44}$ suggested that the bridging water is only weakly bound $(\Delta \mathrm{G}=3.09 \mathrm{kcal} / \mathrm{mol} ; \Delta \mathrm{H}=-1.36 ;-\mathrm{T} \Delta \mathrm{S}=4.45)$, indicating that it could be displaced without a large desolvation penalty (Fig. 2a). Methylation of the pyridone $\mathrm{N}-\mathrm{H}$ would remove one of the two hydrogen-bond interactions with Trp624 and displace the bridging water, as predicted by the docking model of a methylated analog (Fig. 2b). Our analysis and docking model suggested that methylation of the free $\mathrm{NH}$ in the pyridone would be tolerated and that binding energy could be recovered through modification on 
the other parts of the molecule such as the 4-position of the pyridone, as shown by others. ${ }^{45}$

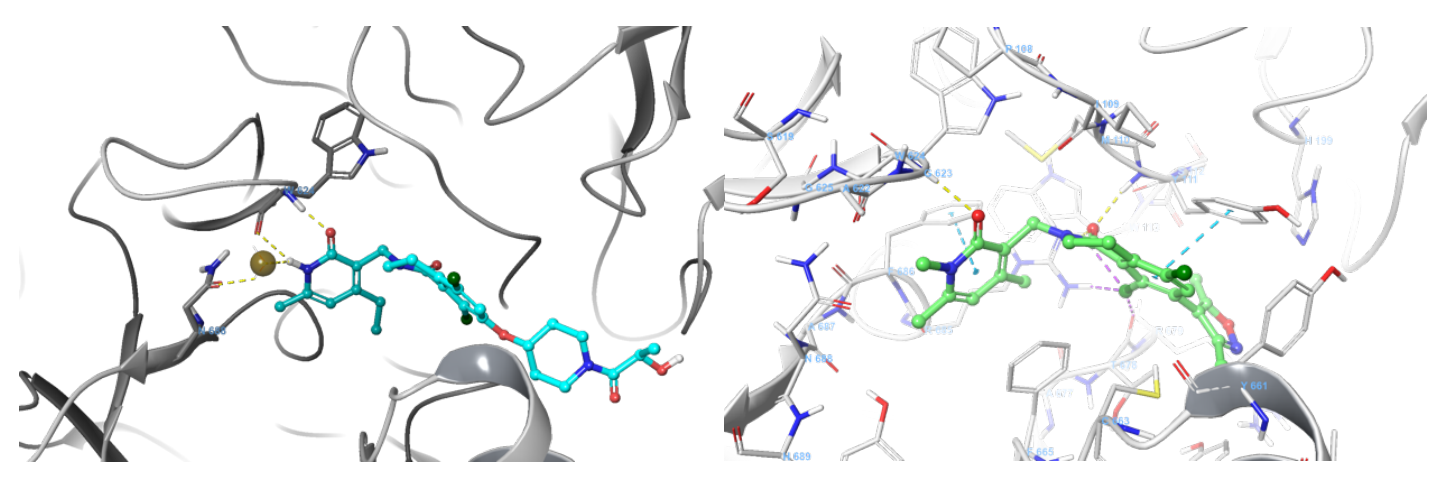

Figure 2. a) Watermap calculation showed de-stabilizing energy at the bridging water hydration site. b) Docking model of methylated pyridone compound 5 in EZH2 (PDB: 5IJ7)

Encouraged by this analysis, we selected a set of disclosed pyridone series EZH2 inhibitors and methylated the $\mathrm{NH}$ group in the conserved dimethylpyridone substituent, reducing the number of hydrogen bond donors and aiming to increase brain penetration. While methylation on the pyridone resulted in an expected reduction in biochemical potency we were still able to identify compounds with low nM activity against EZH2. More importantly, several of these modified EZH2 inhibitors exhibited improved MDR efflux ratios compared to the parent $\mathrm{N}-\mathrm{H}$ pyridone, supporting our strategy of $\mathrm{N}$ methylation on the pyridone. One of these compounds, 5, exhibited an $\mathrm{IC}_{50}$ of $14 \mathrm{nM}$ in our biochemical assay, a modest drop in potency relative to the original compound 2. Compound 5 retained moderate potency in the cellular EZH2 inhibition assay (flow cytometric quantitation of H3K27me3) (Table 1) while displaying a very favorable MDR ratio of 0.95 and good permeability, representing a significant improvement relative to compound 2. Furthermore, the concentration ratio of unbound drug in brain to blood $(\mathrm{Kp}, \mathrm{uu}=0.29)$ obtained from in vivo study in rats demonstrated that compound 5 is brain penetrant in vivo and provided proof-of principle that $\mathrm{N}$-methylation of the pyridone group was sufficient to confer brain penetrance. Unfortunately, the instability toward both human and mouse liver microsomes, as well as, modest in vitro anti-proliferation effect compared to parent compound 2 limited the utility of $\mathbf{5}$ in follow up studies. To utilize this novel class of brain penetrant $\mathrm{EZH} 2$ inhibitor for in vivo studies, we sought to further improve the compound's cell potency and liver microsomal stability. 
Table 1. Methylation of dimethylpyridone to improve BBB<smiles>Cc1cc(C)c(CN2CCc3c(Cl)cc(-c4c(C)noc4C)c(Cl)c3C2=O)c(=O)[nH]1</smiles>

2

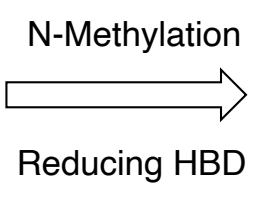

Reducing HBD<smiles>Cc1cc(C)n(C)c(=O)c1CN1CCc2c(Cl)cc(-c3c(C)noc3C)c(Cl)c2C1=O</smiles>

5

\begin{tabular}{|l|l|l|}
\hline & $\mathbf{2}$ & $\mathbf{5}$ \\
\hline EZH2 IC $_{50}(\mathrm{nM})$ & 1.0 & 14 \\
\hline Cellular IC 50 (H3K27me3) $(\mathrm{nM})$ & 16 & 580 \\
\hline Karpas-422 proliferation $(\mathrm{nM})$ & 122 & 4680 \\
\hline $\mathrm{HLM} / \mathrm{MLM}(\mu \mathrm{L} / \mathrm{min} / \mathrm{mg})$ & $210 / 253$ & $449 />768$ \\
\hline $\mathrm{Cl}$ total $(\mu \mathrm{L} / \mathrm{min} / \mathrm{g})$ & 35 & 100 \\
\hline AUCpo $(\mathrm{h} . \mathrm{ng} / \mathrm{mL}) /$ Bioavailability & $67.1 / 13.7 \%$ & $5.8 / 3.5 \%$ \\
\hline $\begin{array}{l}\text { MDCK/MDR1 permeability(nm/s) } \\
\text { AB, efflux ratio }\end{array}$ & $37,4.8$ & $105,0.95$ \\
\hline $\mathrm{K}_{\text {p,uu }}$ & $<0.003$ & 0.29 \\
\hline
\end{tabular}

Our approach to improve potency and metabolic stability was initially guided by literature reports exploring substitution at the 4 position of the pyridone. ${ }^{45}$ These showed that the 4-position of the pyridone ring can accommodate a larger hydrophobic group, which is involved with Van der Waals contacts with hydrophobic residues on the protein. Changes at this position can have a pronounced effect on EZH2 enzyme activity ${ }^{45}$ and we reasoned that the potency loss resulting from $\mathrm{N}$-methylation could be recovered by introducing favorable substituents at the 4-position of the pyridone in our brain penetrant molecules. We then prepared several analogs related to $\mathbf{5}$ in an effort to improve EZH2 inhibition activity (Table 2). When we incorporated increasingly more hydrophobic substituents (compounds 6a-c), we found that the MDR ratios were maintained at a desirable level. However, their biochemical potency dropped dramatically. We did observe moderate improvement in human microsome stability; however, stability against mouse liver microsome remained very low. A methoxy group was incorporated to reduced lipophilicity, anticipating improved microsomal stability predicted by lower AlogP value. Compound $\mathbf{6 d}$ displayed a moderate human liver microsome (HLM) increase, however mouse liver microsomes (MLM), biochemical and cellular potency were similar to compound $\mathbf{5}$. Surprisingly, compound $\mathbf{6 d}$ exhibited a greatly increased MDR ratio suggesting a very narrow SAR space to maintain desirable permeability characteristics. A similar observation was made by incorporation of a 4-thiomethyl pyridone, recently reported to enhance EZH2 potency of compound 4 (Fig. 1) with increased residence time, ${ }^{46}$ to provide compound $6 \mathrm{e}$ which exhibited biochemical and cellular potency similar to parent compound 2. Therefore, while the 4-SMe group was able to restore the potency lost due to $\mathrm{N}$-methylation in compound $\mathbf{5}$, the desirable brain-penetrating properties gained through $\mathrm{N}$-methylation were lost. 
Table 2. SAR on 4-position of the pyridone<smiles>[R4]c1cc(C)n(C)c(=O)c1CN1CCc2c(Cl)cc(-c3c(C)noc3C)c(Cl)c2C1=O</smiles>

\begin{tabular}{|l|l|l|l|l|l|l|}
\hline Compound & $\mathrm{R} 4$ & $\begin{array}{l}\mathrm{EZH} 2 \\
\mathrm{I} \mathrm{C}_{50} \\
(\mathrm{nM})\end{array}$ & $\begin{array}{l}\text { Karpas-422 } \\
\text { Proliferation } \\
(\mathrm{nM})\end{array}$ & $\begin{array}{l}\mathrm{HLM} / \mathrm{MLM} \\
(\mu \mathrm{L} / \mathrm{min} / \mathrm{mg})\end{array}$ & AlogP & $\begin{array}{l}\text { MDCK/MDR1 } \\
\text { permeability(nm/s) } \\
\text { AB, BA/AB }\end{array}$ \\
\hline $\mathbf{5}$ & $\mathrm{Me}$ & 14 & 4680 & $449 />768$ & 4.4 & $105,0.95$ \\
\hline $\mathbf{6 a}$ & $\mathrm{Et}$ & 82 & - & $>768 />768$ & 4.9 & $110,0.72$ \\
\hline $\mathbf{6 b}$ & $\mathrm{c}-\mathrm{Pr}$ & 302 & - & $490 />768$ & 4.7 & $52,1.5$ \\
\hline $\mathbf{6 c}$ & $\mathrm{CF}_{3}$ & $>1000$ & - & $287 / 592$ & 4.9 & $49,2.4$ \\
\hline $\mathbf{6 d}$ & $\mathrm{OMe}$ & 11.6 & 2950 & $117 / 656$ & 3.9 & 10,23 \\
\hline $\mathbf{6 e}$ & $\mathrm{SMe}$ & 1.3 & 632 & $235 / 796$ & 4.5 & 3,110 \\
\hline
\end{tabular}

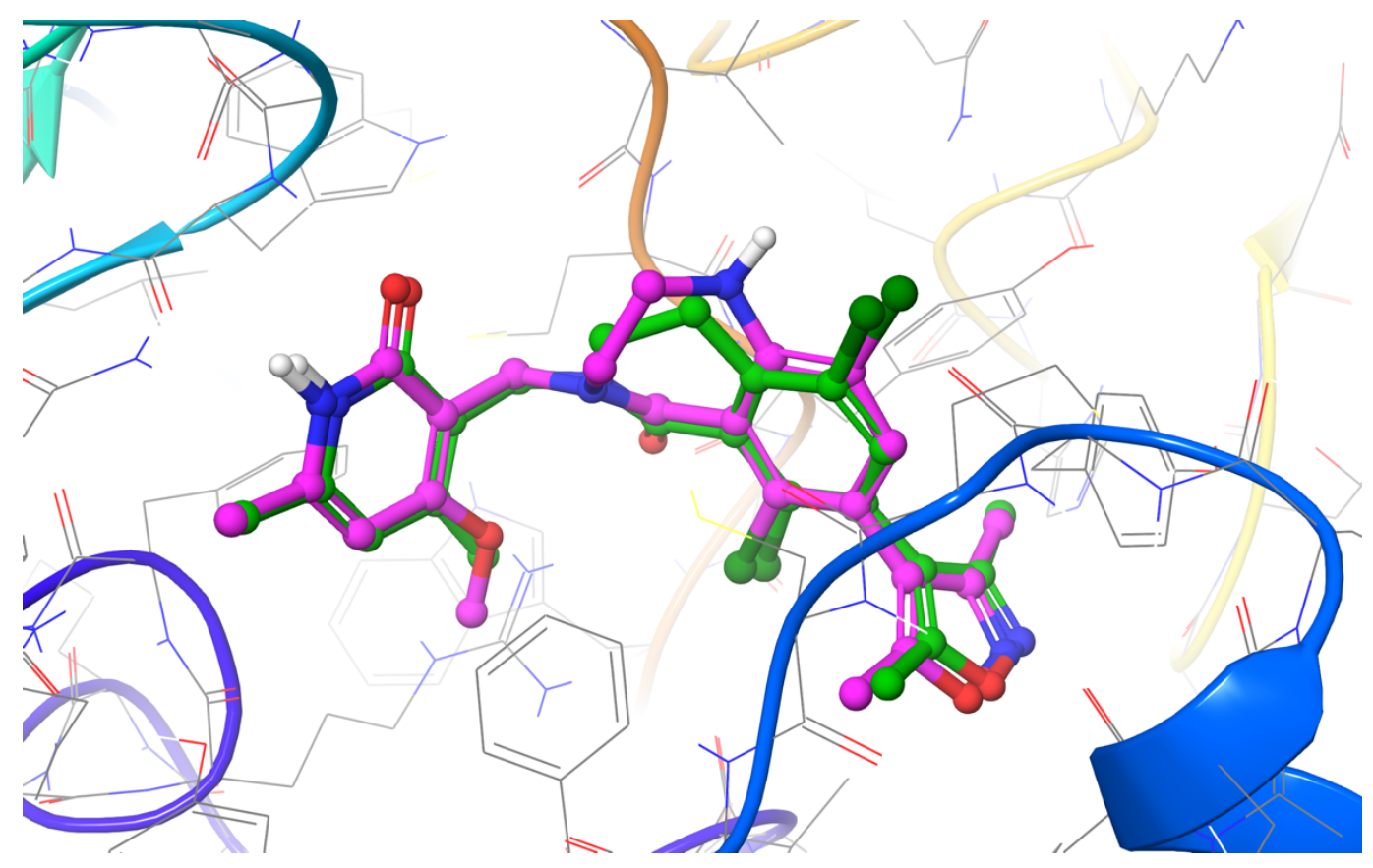

Figure 3. The predicted binding mode between EZH2 and compound 7, overlaid with the crystallographic binding mode of compound 2 from PDBID 6B3W. ${ }^{47}$ The protein is displayed as cartoon ribbons with atoms in grey wire and the crystallographic binding mode of compound 2 is shown as green balls and sticks. The predicted binding mode of compound 7 is shown as magenta balls and sticks. 
Further effort to improve the potency and metabolic stability of N-methyl pyridonecontaining EZH2 inhibitors led us to initiate a medicinal chemistry effort to identify a new class of scaffold. Kung et al. showed that a seven-membered-ring analog related to compound 2 exhibited comparable potency and metabolic stability. ${ }^{39}$ Our modeling studies based on crystal data (Fig. 3) showed that there is overall good overlay between 6- and 7-membered-ring structures. The expanded 7-membered ring occupied a similar space with potential for additional interactions with the protein. Guided by our computational docking model, we then prepared several analogs related to compound 2 (Table 3) with progressively larger substituents R1 at the aniline nitrogen. We chose to use the 4-OMe pyridone because it imparted higher microsomal stability (likely due to lower lipophilicity), as well as slightly more potent EZH2 biochemical activity. Our first set of compounds included $7\left(R_{1}=H\right)$ and $8\left(R_{1}=M e\right)$, which both exhibited subnanomolar potency in the biochemical assay and were as potent as the parent 6membered ring compound 2. The enhanced biochemical potency translated into similar or better potency in cellular H3K27me3 assays and antiproliferation assays (Table 3). Compounds 7 and 8 also displayed improvements in HLM/MLM stability parameters relative to the analogous 6-membered-ring compound 2, presumably attributed to the decrease in AlogP values by incorporating the additional nitrogen in the 7-membered ring. Substitution of the aniline nitrogen with a larger ethyl group, compound 9, displayed dramatic attenuation of biochemical potency. It is unclear whether the potency drop was caused by the conformation change in the 7-membered ring due to steric repulsion between the ethyl group and the $\mathrm{Cl}$ group, or simply steric hinderance in the binding pocket to accommodate the ethyl group that is not predicted by our docking model. By removing the $\mathrm{Cl}$ group, we anticipated that a less restricted conformation would be populated due to the relief of steric hinderance, and at the same time, further reduction of AlogP will bring the HLM/MLM stability to a favorable level. We then prepared analogous des-Cl compounds $10\left(R_{1}=H\right)$ and $11\left(R_{1}=M e\right)$. Compound 10 displayed a modest loss in biochemical potency and antiproliferation efficacy, which is consistent with the effect of $\mathrm{Cl}$ substituent in the 6-membered ring reported in the literature. ${ }^{39}$ Interestingly, the decrease in AlogP resulted in significant improvement in both HLM and MLM stability. Unexpectedly, the ethyl substituted compound 11 exhibited more significant potency loss and we decided not to pursue more extensive SAR at this position.

Table 3. SAR on 7-membered-ring scaffold<smiles>[R2]c1cc(-c2c(C)noc2C)c(Cl)c2c1N([R1])CCN(Cc1c(OC)cc(C)[nH]c1=O)C2=O</smiles><smiles>Cc1cc(C)c(CN2CCc3c(Cl)cc(-c4c(C)noc4C)c(Cl)c3C2=O)c(=O)[nH]1</smiles> 


\begin{tabular}{|l|l|l|l|l|l|l|l|l|}
\hline $\begin{array}{l}\text { Com } \\
\text { pou } \\
\text { nd }\end{array}$ & R1 & R2 & $\begin{array}{l}\text { EZH2 } \\
\text { IC50 } \\
(\mathrm{nM})\end{array}$ & $\begin{array}{l}\text { Cell IC } 50 \\
(\mathrm{H} 3 \mathrm{~K} 27 \mathrm{me} \\
3)(\mathrm{nM})\end{array}$ & $\begin{array}{l}\text { Karpas- } \\
422 \\
\begin{array}{l}\text { Prolif/n } \\
(\mathrm{nM})\end{array}\end{array}$ & $\begin{array}{l}\text { HLM/MLM } \\
(\mu \mathrm{L} / \mathrm{min} / \mathrm{mg})\end{array}$ & AlogP & $\begin{array}{l}\text { MDCK/MDR1 } \\
\text { permeability(nm/s) } \\
\text { AB, BA/AB }\end{array}$ \\
\hline $\mathbf{2}$ & & & 1.0 & 16 & 122 & $210 / 253$ & 3.9 & $37,4.8$ \\
\hline $\mathbf{7}$ & $\mathrm{H}$ & $\mathrm{Cl}$ & 0.35 & 17 & 65 & $79 / 123$ & 3.0 & $<1,>51$, \\
\hline $\mathbf{8}$ & $\mathrm{Me}$ & $\mathrm{Cl}$ & 0.87 & 208 & 245 & $80 / 112$ & 3.3 & $<1,>49$ \\
\hline $\mathbf{9}$ & $\mathrm{Et}$ & $\mathrm{Cl}$ & 33.4 & - & - & - & 3.7 & - \\
\hline $\mathbf{1 0}$ & $\mathrm{Me}$ & $\mathrm{H}$ & 2.9 & & 1350 & $9 /-7$ & 2.6 & $<1,>19$ \\
\hline $\mathbf{1 1}$ & $\mathrm{Et}$ & $\mathrm{H}$ & 489 & - & - & - & 3.0 & - \\
\hline
\end{tabular}

The potency and metabolic stability profile of compound 8 led us to explore this substitution pattern in conjunction with SAR at the $R_{3}$ position (Table 4). More importantly, we chose compound $\mathbf{8}$ over the slightly more potent compound $\mathbf{7}$ as the starting point because it has one less hydrogen bond donor which would have reduced efflux potential. The substitution explored at the $R_{3}$ position included moieties previously demonstrated by us and others in the 6-membered ring lactam scaffold to display potent biochemical inhibition of EZH2 and/or good metabolic stability. ${ }^{40}$ We were curious to find out if SAR previously established was transferable to the new 7-membered ring lactam scaffold. It was shown that introduction of the $\mathrm{sp}^{3}$-carbon atom at this position was tolerated. Substitution of the $R_{3}$ position with an isopropyl group (12) in compound 8 resulted in significant loss of potency, suggesting that dimethylisoxazole made similar hydrophobic interactions with the protein as the 6-membered ring lactam scaffold as predicted in the docking model. We then extended the isopropyl group with a branched tetrahydropyran $(\mathbf{1 3}, \mathbf{1 5})$ to fill the two hydrophobic binding pockets occupied by the dimethylisoxazole, either through a carbon or nitrogen linkage. Both compounds 13 and 15 indeed displayed similar potency to compound 8 but with much lower HLM/MLM stability. Reduction of AlogP through a hydroxyl group (14) increased HLM/MLM stability with modest loss of potency. Replacement of dimethylisoxazole with aromatic moieties $(16$ - 18) that we identified in the 6-membered ring lactam series maintained the microsomal stability but displayed significant loss of potency in the new series.

Table 4: SAR for dimethylisoxazole replacement<smiles>[R3]c1cc(Cl)c2c(c1Cl)C(=O)N(Cc1c(OC)cc(C)[nH]c1=O)CCN2C</smiles>

\begin{tabular}{|l|l|ll|l|l|}
\hline Compound & R3 & $\begin{array}{l}\text { EZH2 } \\
(\mathrm{nM})\end{array}$ & $\begin{array}{l}\text { IC }) \\
\text { (HLM/MLM } \\
(\mu \mathrm{L} / \mathrm{min} / \mathrm{mg})\end{array}$ & AlogP \\
\hline $\mathbf{8}$ & 0.87 & $80 / 112$ & 3.3 \\
\hline
\end{tabular}




\begin{tabular}{|c|c|c|c|c|}
\hline 12 & 5 & 33.4 & $29,>768$ & 3.7 \\
\hline 13 & & 2.0 & 206,562 & 4.1 \\
\hline 14 & $\mathrm{HC}$ & 9.4 & 34,91 & 3.4 \\
\hline 15 & & 1.9 & $181,>768$ & 3.3 \\
\hline 16 & & 64.8 & $-7,8$ & 4.3 \\
\hline 17 & & 72.1 & 97,297 & 5.3 \\
\hline 18 & & 220 & 41,41 & 4.2 \\
\hline
\end{tabular}

To access potent EZH2 inhibitors with favorable brain penetrating properties, we reasoned that the potency profile of the 6,7-scaffold in combination with substitution to either increase lipophilicity or mask hydrogen bond donor functionality would provide a balanced profile to test this drug concept. To this end, we explored replacement of the 4-OMe group with the more lipophilic 4-ethyl substituted pyridone. Unfortunately the resulting compound 19 displayed has no obvious advantage in permeability relative to compound 8 and also appeared to have a similar potency. This was surprising since this substitution has been associated with enhanced EZH2 potency through increasing residence time.$^{46}$ However, the SAR analysis for high affinity compounds is complicated by the enzymatic assay protein concentration of $5 \mathrm{nM}$ resulting in a floor of the assay of $2.5 \mathrm{nM}$. For example, incorporation of the $\mathrm{N}$-methyl pyridone into compound 20 displayed a greater than 500 -fold loss of potency relative to compound $\mathbf{8}$ but the exact magnitude of the loss is unclear.

During the course of our program, Khanna et. al disclosed that incorporating a 4thiomethyl pyridone in CPI-1205 (4) as a key modification significantly increased biochemical and cellular potency due to prolonged residence time, leading to the development of $2^{\text {nd }}$ generation EZH2 inhibitor CPI-0209 with extended target coverage. ${ }^{49} \mathrm{We}$ incorporated this finding into our new 7 -membered ring structure of 
EZH2 inhibitor. The resulting compound, compound 21, exhibited similar biochemical potency relative to compound 8 but superior cellular efficacy ( $>30$-fold improvement), consistent with the literature finding. Importantly, this improvement translated to markedly enhanced potency in anti-proliferation assays in Karpas-422 cells, comparable to those of other reported EZH2 inhibitors including the clinically approved Tazemetostat control. Despite the desirable potency, this compound proved to be a significant MDR substrate and therefore was not suitable for advancement as a brainpenetrant analogue. Nevertheless, the efficacy improvement from the thiomethyl pyridone was very encouraging. Accordingly, we prepared the analogous $\mathrm{N}$-methyl pyridone compound 22. Although we did observe a significant improvement in biochemical potency for compound 22 versus $\mathbf{2 0}$, this compound still suffered from poor cellular efficacy. Removal of the R1 methyl group (23) provided a further improvement in both biochemical and cellular efficacy. Unfortunately, these compounds still displayed high value of MDCK/MDR1 ratio, suggesting that they are good substrates for efflux transporters and would not likely achieve significant brain penetration.

Table 5. Thiomethyl pyridone analogues with 7-membered ring structure.

\begin{tabular}{|c|c|c|c|c|c|c|}
\hline Compound & R1 & R5 & $\begin{array}{l}\mathrm{EZH} 2 \\
\mathrm{IC} \mathrm{C}_{50} \\
(\mathrm{nM}) \\
\end{array}$ & $\begin{array}{lr}\text { Cell } \quad \mathrm{IC}_{50} \\
(\mathrm{H} 3 \mathrm{~K} 27 \mathrm{Me} 3) \\
(\mathrm{nM})\end{array}$ & $\begin{array}{l}\text { Karpas-422 } \\
\text { Proliferation } \\
\text { (nM) }\end{array}$ & $\begin{array}{l}\text { MDCK/MDR1 } \\
\text { permeability }(\mathrm{nm} / \mathrm{s}) \\
\mathrm{AB}, \mathrm{BA} / \mathrm{AB}\end{array}$ \\
\hline 8 & $\mathrm{Me}$ & & 0.87 & 208 & 245 & $<1,>49$ \\
\hline 19 & $\mathrm{Me}$ & & 1.8 & & & $<1,>170$ \\
\hline 20 & $\mathrm{Me}$ & & 541 & & & \\
\hline & & & & & & \\
\hline & & & & & & \\
\hline
\end{tabular}




\begin{tabular}{|c|c|c|c|c|c|c|}
\hline 21 & $\mathrm{Me}$ & $\mathrm{O}$ & 0.9 & 6.0 & 125 & $<1,>99$ \\
\hline 22 & $\mathrm{Me}$ & 0 & 11.4 & 1550 & 10380 & 2,110 \\
\hline 23 & $\mathrm{H}$ & ด & 2.1 & 167 & 1320 & 2,220 \\
\hline
\end{tabular}

\section{Conclusion}

Utilizing structure-based drug design a novel and highly potent class of 6,7-fused EZH2 inhibitors was identified. This series provided compounds with sub-nanomolar enzymatic activity and potent antiproliferative effects. Enhanced inhibition of cellular trimethylation could be achieved by compound 21 (TDI-11904), derived from incorporation of thiomethyl substitution on the key pyridone moiety (8 vs 21). This is in line with reports of improved on target residence time with this substitution on a different scaffold. ${ }^{46}$ Our results demonstrate that this is a general effect that can be applied to different chemical series of EZH2 inhibitors. Additionally, a new strategy to create brain penetrant EZH2 inhibitors through methylation of the conserved pyridone found in many EZH2 inhibitors was described. Compound 5 (TDI-6118) displayed brain penetrating properties both in vitro and in vivo, and marks the first report of a brain penetrant EZH2 inhibitor. The improved efflux ratio observed with compound $\mathbf{5}$ could not be maintained with either further modification on the pyridone or with the change to the 7-membered ring lactam structure. However, the enzymatic potency seen by combining the $\mathrm{N}$ methylation with pyridone substitution for increased residence time (e.g. 22) suggests that additional structural modifications or alternate cores may provide compounds that balance high-potency (and anti-proliferative effects) with brain penetrance.

\section{Chemistry}

Synthesis of $R_{1}$ methyl-substituted 7-membered lactam was accomplished starting from 2-amino-3,6-dichlorobenzoic acid 24 (Scheme 1). Bromination of compound $\mathbf{2 4}$ followed by reductive amination of compound 25 with N-Boc-2-aminoaldehyde 26 afforded bromide carboxylic acid 27 . Treatment of 27 with $\mathrm{HCl}$ deprotected the Boc group from the amine moiety, and subsequent cyclization under amide coupling condition generated the lactam intermediate $\mathbf{2 9}$, which upon methylation afforded intermediate $\mathbf{3 0}$. 


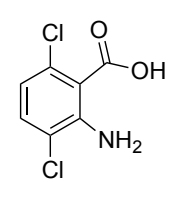

24

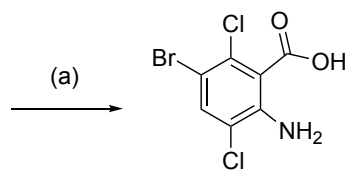

25

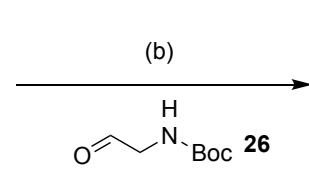

Clle (e)

30

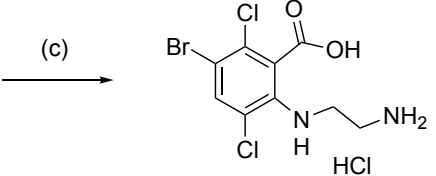

28

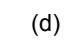<smiles>O=C1NCCNc2c(Cl)cc(Br)c(Cl)c21</smiles>

29

Scheme 1. Synthesis of 7-membered ring core bromides 29 and 30. Reagents and conditions: (a) NBS, DMF, RT; (b) $\mathrm{NaBH} 4, \mathrm{AcOH}, \mathrm{DCE}, 60^{\circ} \mathrm{C}, 12 \mathrm{~h}$; (c) $4 \mathrm{M} \mathrm{HCl}$ in dioxane, RT; (d) HOBt, BOP, NMM, DMF, RT, $16 \mathrm{~h}$; (e) TEA, Mel, DMF, $70^{\circ} \mathrm{C}, 16 \mathrm{~h}$.

Benzyloxy-protected chloromethylpyridine intermediate 31 was prepared from commercially available 2-hydroxy-4-methoxy-6-methylpyridine-3-carbonitrile according to literature procedure. ${ }^{39}$ Alkylation of the lactam nitrogen in intermediates $\mathbf{2 9}$ and $\mathbf{3 0}$ with the chloride intermediate 31 under basic conditions afforded the common intermediates $\mathbf{3 2}$ and $\mathbf{3 3}$ (Scheme 2). Suzuki coupling with dimethylisoxazole boronic acid 34 followed by the removal of benzyl protecting group with TFA afforded the final compounds 8 and 9.
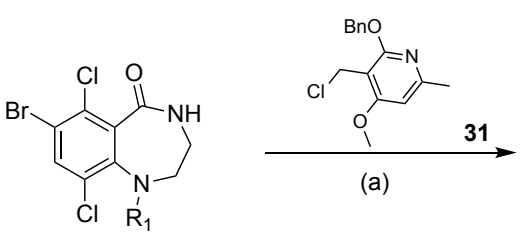

(a)

$$
29 \mathrm{R} 1=\mathrm{H}
$$

$30 \mathrm{R} 1=\mathrm{Me}$

(c)

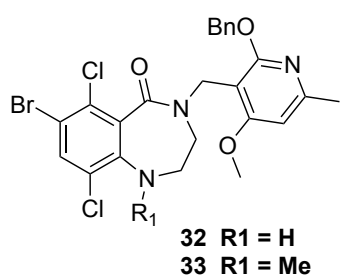

$33 \mathrm{R} 1=\mathrm{Me}$

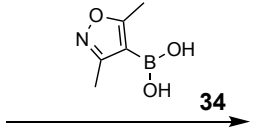

(b)

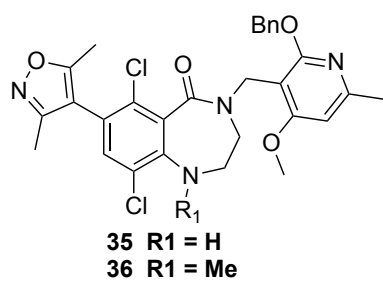

Scheme 2. Synthesis of compounds 8 and 9. Reagents and conditions: (a) $t$-BuOK, DMF for 29; $\mathrm{NaH}$, DMF for 30, 40 $\mathrm{C}, 30 \mathrm{~min}$; (b) $\mathrm{Pd}(\mathrm{dppf}) \mathrm{Cl}_{2}, \mathrm{~K}_{3} \mathrm{PO}_{4}$, dioxane, $\mathrm{H}_{2} \mathrm{O}, 90^{\circ} \mathrm{C}, 2 \mathrm{~h}$; (c) TFA, DCM, RT, $16 \mathrm{~h}$.

Compound 12 was prepared through two sequential alkylations (Scheme 3), one with 2iodopropane on hydroxyl group of phenol intermediate 38, the other with chloride intermediate 31 on $\mathrm{NH}$ group of amide intermediate 39. Compounds 13 was accessed through two Grinard reactions (Scheme 4) starting from bromide intermediate 33. The first Grignard reaction with 4-formyl tetrahydropyran gave secondary alcohol intermediate 41, which was either subjected to acidic condition to provide compound 14, or oxidation condition to ketone intermediate 42. The second Grignard reaction 
generated tertiary alcohol intermediate 43 which was converted to compound 13 by elimination under acidic conditions.<smiles>CN1CCNC(=O)c2c(Cl)c(Br)cc(Cl)c21</smiles>

(a)<smiles>CN1CCNC(=O)c2c(Cl)c(B(O)O)cc(Cl)c21</smiles>

(b)<smiles>CN1CCNC(=O)c2c(Cl)c(O)cc(Cl)c21</smiles><smiles>CC(C)Oc1cc(Cl)c2c(c1Cl)C(=O)NC[CH2+]2</smiles>

39<smiles>COc1cc(C)nc(OCc2ccccc2)c1CCl</smiles>

(d)<smiles>COc1cc(C)nc(O)c1CN1CCN(C)c2c(Cl)cc(OC(C)C)c(Cl)c21</smiles>

(e)

Scheme 3. Synthesis of compound 12. Reagents and conditions: (a) Bis(pinacolato)diborane, $\mathrm{Pd}$ (dppf) $\mathrm{Cl}_{2}$, $\mathrm{KOAc}$, dioxane, $90^{\circ} \mathrm{C}, 3 \mathrm{~h}$; (b) $\mathrm{H}_{2} \mathrm{O}_{2}, \mathrm{NaOH}$, THF, water, $25^{\circ} \mathrm{C}, 2 \mathrm{~h}$; (c) 2-iodopropane, DMF, $\mathrm{K}_{2} \mathrm{CO}_{3}, 40^{\circ} \mathrm{C}, 2 \mathrm{~h}$; (d) $31, \mathrm{NaH}, \mathrm{DMF}, 40^{\circ} \mathrm{C}, 1 \mathrm{~h}$; (e) TFA, DCM, $45^{\circ} \mathrm{C}, 1.5 \mathrm{~h}$.<smiles>COc1cc(C)nc(OCc2ccc(C)cc2C)c1CN1CCN(C)c2c(OC)c(Cl)cc(Br)c2C1=O</smiles><smiles>COc1cc(C)nc(OC)c1CN1CCN(C)c2c(Cl)cc(C(O)(O)C3CCOCC3)c(Cl)c2C1=O</smiles>

(e)

Scheme 4. Synthesis of compounds 13-14. Reagents and conditions: (a) $i$-PrMgCl, THF, -65 to $10^{\circ} \mathrm{C}$, $1.5 \mathrm{~h}$; (b) TFA, DCM, $45^{\circ} \mathrm{C}, 1.5 \mathrm{~h}$; (c) Dess-Martin, DCM, $15^{\circ} \mathrm{C}, 12 \mathrm{~h}$; (d) MeMgBr, THF, $0^{\circ} \mathrm{C}, 2 \mathrm{~h}$; (e) $\mathrm{Et}_{3} \mathrm{SiH}, \mathrm{TFA}, 0-45^{\circ} \mathrm{C}, 4 \mathrm{~h}$;

Compound 15 was prepared through reductive amination using amine intermediate 44 (Scheme $5)$, which was generated by amination of the bromide 33. Compounds 16-18 with aromatic R3 substitutions (Scheme 6) were synthesized via Suzuki reaction using the corresponding commercial boronic acids 47-49. Methylation of $\mathrm{NH}$ group in pyridone followed the general procedure (Scheme 7). 
33

(a) $\mathrm{NH}_{2} \mathrm{Boc}$

(b)

(d)

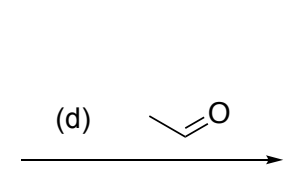<smiles>COc1cc(C)nc(OCc2ccccc2)c1CN1CCN(C)c2c(Cl)cc(N)c(Cl)c2C1=O</smiles>

(c)

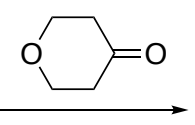<smiles>COc1cc(C)nc(OCc2ccccc2)c1CN1CCN(C)c2c(Cl)cc(NC3CCOCC3)c(Cl)c2C1=O</smiles>

(e)<smiles>COc1cc(C)nc(OCc2ccccc2)c1CN1CCN(C)c2c(Cl)cc(N(C)C3CCOCC3)c(Cl)c2C1=O</smiles>

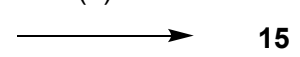

Scheme 5. Synthesis of compounds 15. Reagents and conditions: (a) $\mathrm{Pd}(\mathrm{dba})_{2}$, xantphos, $\mathrm{Cs}_{2} \mathrm{CO}_{3}$, dioxane, $110^{\circ} \mathrm{C}, 2 \mathrm{~h}$; (b) $\mathrm{HCl} / \mathrm{EtOAC}, 15^{\circ} \mathrm{C}, 2 \mathrm{~h}$; (c) Tetrahydropyran-4-one, tetramethylammonium, triacetoxyboranuide, TFA, DCM, $15^{\circ} \mathrm{C}, 2 \mathrm{~h} ; \quad$ (d) Acetaldehyde, tetramethylammonium, triacetoxyboranuide, TFA, DCM, $15^{\circ} \mathrm{C}, 2 \mathrm{~h}$; (e) TFA, DCM, $45^{\circ} \mathrm{C}, 2 \mathrm{~h}$.

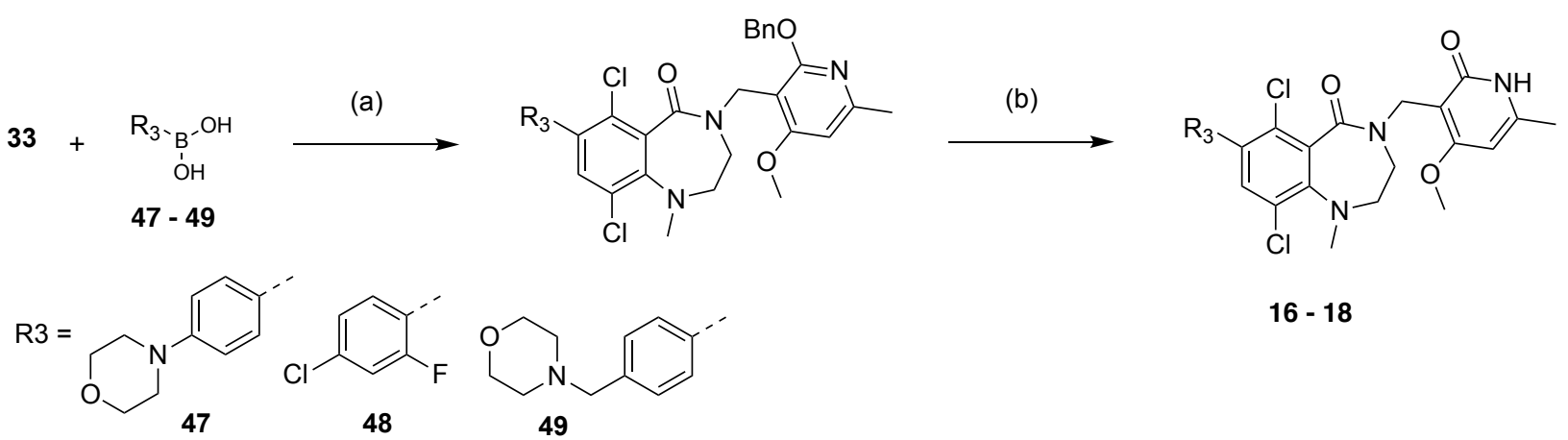

Scheme 6. Synthesis of compounds 16-18. Reagents and conditions: (a) $\mathrm{Pd}(\mathrm{dppf}) \mathrm{Cl}_{2}, \mathrm{~K}_{3} \mathrm{PO}_{4}$ or CsF, dioxane, $\mathrm{H}_{2} \mathrm{O}, 90^{\circ} \mathrm{C}, 2 \mathrm{~h}$; (b) TFA, DCM, RT, $16 \mathrm{~h}$.<smiles>[Y]c1cc(C)[nH]c(=O)c1CN1CCN([R1])c2c(Cl)cc(-c3c(C)noc3C)c(Cl)c21</smiles>

$\mathrm{R} 1=\mathrm{H}$ or $\mathrm{Me}$

$\mathrm{X}=\mathrm{OMe}$ or SMe

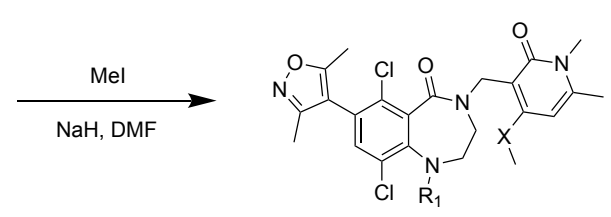

Scheme 7. General procedure for N-methylation of pyridone. Reagents and conditions: NaH, Mel, DMF, $0-20^{\circ} \mathrm{C}$ for $12 \mathrm{~h}$.

\section{Acknowledgements}

The authors gratefully acknowledge the support to the project generously provided by the Tri-Institutional Therapeutics Discovery Institute (TDI), a 501(c)(3) organization. TDI receives financial support from Takeda Pharmaceutical Company, TDl's parent institutes (Memorial Sloan Kettering Cancer Center, The Rockefeller University and Weill Cornell Medicine) and from a generous contribution from Mr. Lewis Sanders and other philanthropic sources. RP is supported by the MSK IDEA Award and the Center for Experimental Therapeutics, The Cure Starts Now and Team Jack Foundation. 


\section{References}

1.McLendon R, Friedman A, Bigner $D$, et al. Comprehensive genomic characterization defines human glioblastoma genes and core pathways. Nature. 2008;455(7216): 10611068.

2.Valencia AM, Kadoch C. Chromatin regulatory mechanisms and therapeutic opportunities in cancer. Nature Cell Biology. 2019;21(2): 152-161.

3. Schuettengruber B, Chourrout D, Vervoort M, Leblanc B, Cavalli G. Genome regulation by polycomb and trithorax proteins. Cell. 2007;128(4): 735-745.

4. Cao R, Wang L, Wang $\mathrm{H}$, et al. Role of histone $\mathrm{H} 3$ lysine 27 methylation in Polycomb-group silencing. Science. 2002;298(5595): 1039-1043.

5. Schuettengruber B, Bourbon HM, Di Croce L, Cavalli G. Genome Regulation by Polycomb and Trithorax: 70 Years and Counting. Cell. 2017;171(1): 34-57.

6. Kim KH, Roberts CWM. Targeting EZH2 in cancer. Nature Medicine. 2016;22(2): 128-134.

7. Knutson SK, Warholic NM, Wigle TJ, et al. Durable tumor regression in genetically altered malignant rhabdoid tumors by inhibition of methyltransferase EZH2. Proceedings of the National Academy of Sciences. 2013;110(19): 7922.

8. Vaswani RG, Gehling VS, Dakin LA, et al. Identification of (R)-N-((4-Methoxy-6methyl-2-oxo-1,2-dihydropyridin-3-yl)methyl)-2-methyl-1-(1-(1-(2,2,2-

trifluoroethyl)piperidin-4-yl)ethyl)-1H-indole-3-carboxamide (CPI-1205), a Potent and Selective Inhibitor of Histone Methyltransferase EZH2, Suitable for Phase I Clinical Trials for B-Cell Lymphomas. Journal of Medicinal Chemistry. 2016;59(21): 9928-9941.

9. Honma D, Kanno O, Watanabe J, et al. Novel orally bioavailable EZH1/2 dual inhibitors with greater antitumor efficacy than an EZH2 selective inhibitor. Cancer Sci. 2017;108(10): 2069-2078.

10. Sneeringer CJ, Scott MP, Kuntz KW, et al. Coordinated activities of wild-type plus mutant EZH2 drive tumor-associated hypertrimethylation of lysine 27 on histone H3 (H3K27) in human B-cell lymphomas. Proceedings of the National Academy of Sciences. 2010;107(49): 20980.

11. Wigle TJ, Knutson SK, Jin L, et al. The Y641C mutation of EZH2 alters substrate specificity for histone H3 lysine 27 methylation states. FEBS Lett. 2011;585(19): 30113014.

12. Bitler BG, Aird KM, Garipov A, et al. Synthetic lethality by targeting EZH2 methyltransferase activity in ARID1A-mutated cancers. Nat Med. 2015;21(3): 231-238. 
13. Helming KC, Wang X, Roberts CWM. Vulnerabilities of mutant SWI/SNF complexes in cancer. Cancer Cell. 2014;26(3): 309-317.

14. Wilson BG, Wang $X$, Shen $X$, et al. Epigenetic Antagonism between Polycomb and SWI/SNF Complexes during Oncogenic Transformation. Ibid.2010;18(4): 316-328.

15. Kennison JA, Tamkun JW. Dosage-dependent modifiers of polycomb and antennapedia mutations in Drosophila. Proceedings of the National Academy of Sciences. 1988;85(21): 8136.

16. Tamkun JW, Deuring R, Scott MP, et al. brahma: A regulator of Drosophila homeotic genes structurally related to the yeast transcriptional activator SNF2SWI2. Cell. 1992;68(3): 561-572.

17. Groisberg R, Subbiah V. EZH2 inhibition for epithelioid sarcoma and follicular lymphoma. The Lancet Oncology. 2020;21(11): 1388-1390.

18. Stacchiotti S, Schoffski $P$, Jones $R$, et al. Safety and efficacy of tazemetostat, a firstin-class EZH2 inhibitor, in patients (pts) with epithelioid sarcoma (ES) (NCT02601950). Journal of Clinical Oncology. 2019;37(15_suppl): 11003-11003.

19. Lin X, DeAngelis LM. Treatment of Brain Metastases. J Clin Oncol. 2015;33(30): 3475-3484.

20. Hall WA, Djalilian HR, Nussbaum ES, Cho KH. Long-term survival with metastatic cancer to the brain. Medical Oncology. 2000;17(4): 279-286.

21. Tabouret E, Chinot $O$, Metellus $P$, Tallet A, Viens $P$, Gonçalves A. Recent trends in epidemiology of brain metastases: an overview. Anticancer Res. 2012;32(11): 46554662.

22. Gardner EE, Lok BH, Schneeberger VE, et al. Chemosensitive Relapse in Small Cell Lung Cancer Proceeds through an EZH2-SLFN11 Axis. Cancer Cell. 2017;31(2): 286-299.

23. Bitler BG, Aird KM, Garipov A, et al. Synthetic lethality by targeting EZH2 methyltransferase activity in ARID1A-mutated cancers. Nat Med. 2015;21(3): 231-238.

24. Tiffen JC, Gunatilake D, Gallagher SJ, et al. Targeting activating mutations of EZH2 leads to potent cell growth inhibition in human melanoma by derepression of tumor suppressor genes. Oncotarget. 2015;6(29): 27023-27036.

25. Zingg D, Debbache J, Schaefer SM, et al. The epigenetic modifier EZH2 controls melanoma growth and metastasis through silencing of distinct tumour suppressors. Nature Communications. 2015;6(1): 6051. 
26. QuickStats: Brain Cancer Death Rates Among Children and Teens Aged 1-19 Years, by Sex and Age Group - United States, 2013-2015. MMWR Morb Mortal Wkly Rep 2017;66:461. . 2017.

27. Mohammad F, Weissmann S, Leblanc B, et al. EZH2 is a potential therapeutic target for H3K27M-mutant pediatric gliomas. Nature Medicine. 2017;23(4): 483-492.

28. Piunti A, Hashizume R, Morgan MA, et al. Therapeutic targeting of polycomb and BET bromodomain proteins in diffuse intrinsic pontine gliomas. Nat Med. 2017;23(4): 493-500.

29. Michealraj KA, Kumar SA, Kim LJY, et al. Metabolic Regulation of the Epigenome Drives Lethal Infantile Ependymoma. Cell. 2020;181(6): 1329-1345.e1324.

30. Knutson SK, Warholic NM, Wigle TJ, et al. Durable tumor regression in genetically altered malignant rhabdoid tumors by inhibition of methyltransferase EZH2. Proceedings of the National Academy of Sciences. 2013;110(19): 7922.

31. Lindsay $H$, Kogiso $M$, Qi $L$, et al. AT-01THERAPEUTIC TARGETING OF INI1 DEFICIENCY IN PEDIATRIC ATRT: A PRE-CLINICAL STUDY UTILIZING PATIENT DERIVED ORTHOTOPIC XENOGRAFT (PDOX) MODELS. Neuro-Oncology. 2015;17(suppl_3): iii1-iii1.

32. Rankovic Z. CNS Drug Design: Balancing Physicochemical Properties for Optimal Brain Exposure. Journal of Medicinal Chemistry. 2015;58(6): 2584-2608.

33. Desai PV, Raub TJ, Blanco MJ. How hydrogen bonds impact P-glycoprotein transport and permeability. Bioorg Med Chem Lett. 2012;22(21): 6540-6548.

34. Di L, Artursson P, Avdeef A, et al. The Critical Role of Passive Permeability in Designing Successful Drugs. ChemMedChem. 2020;15(20): 1862-1874.

35. Di L, Kerns EH, Carter GT. Strategies to assess blood-brain barrier penetration. Expert Opinion on Drug Discovery. 2008;3(6): 677-687.

36. Hitchcock SA. Structural Modifications that Alter the P-Glycoprotein Efflux Properties of Compounds. Journal of Medicinal Chemistry. 2012;55(11): 4877-4895.

37. Di L, Rong H, Feng B. Demystifying Brain Penetration in Central Nervous System Drug Discovery. Ibid.2013;56(1): 2-12.

38. Rankovic Z. CNS Drug Design: Balancing Physicochemical Properties for Optimal Brain Exposure. Ibid.2015;58(6): 2584-2608. 
39. Kung P-P, Rui E, Bergqvist $S$, et al. Design and Synthesis of Pyridone-Containing 3,4-Dihydroisoquinoline-1(2H)-ones as a Novel Class of Enhancer of Zeste Homolog 2 (EZH2) Inhibitors. Ibid.2016;59(18): 8306-8325.

40. Kung P-P, Bingham P, Brooun A, et al. Optimization of Orally Bioavailable Enhancer of Zeste Homolog 2 (EZH2) Inhibitors Using Ligand and Property-Based Design Strategies: Identification of Development Candidate (R)-5,8-Dichloro-7(methoxy(oxetan-3-yl)methyl)-2-((4-methoxy-6-methyl-2-oxo-1,2-dihydropyridin-3yl)methyl)-3,4-dihydroisoquinolin-1(2H)-one (PF-06821497). Ibid.2018;61(3): 650-665.

41. Vaswani RG, Gehling VS, Dakin LA, et al. Identification of (R)-N-((4-Methoxy-6methyl-2-oxo-1,2-dihydropyridin-3-yl)methyl)-2-methyl-1-(1-(1-(2,2,2-

trifluoroethyl)piperidin-4-yl)ethyl)-1H-indole-3-carboxamide (CPI-1205), a Potent and Selective Inhibitor of Histone Methyltransferase EZH2, Suitable for Phase I Clinical Trials for B-Cell Lymphomas. Ibid.2016;59(21): 9928-9941.

42. Zhang P, de Gooijer MC, Buil LCM, Beijnen JH, Li G, van Tellingen O. ABCB1 and ABCG2 restrict the brain penetration of a panel of novel EZH2-Inhibitors. International Journal of Cancer. 2015;137(8): 2007-2018.

43. Brooun A, Gajiwala KS, Deng Y-L, et al. Polycomb repressive complex 2 structure with inhibitor reveals a mechanism of activation and drug resistance. Nature Communications. 2016;7(1): 11384.

44. Young T, Abel R, Kim B, Berne BJ, Friesner RA. Motifs for molecular recognition exploiting hydrophobic enclosure in protein-ligand binding. Proceedings of the National Academy of Sciences. 2007;104(3): 808.

45. Yang X, Li F, Konze KD, et al. Structure-Activity Relationship Studies for Enhancer of Zeste Homologue 2 (EZH2) and Enhancer of Zeste Homologue 1 (EZH1) Inhibitors. J Med Chem. 2016;59(16): 7617-7633.

46. Avinash Khanna AC, Shilpi Arora, Ludivine Moine, Victor S Gehling, Jehrod Brenneman,, Nico Cantone JIS, Shruti Apte, Ashwin Ramakrishnan, Kamil Bruderek, William D., Bradley JEA, Richard T. Cummings, Robert J. Sims, Patrick Trojer, and Julian R. Levell. Design, Synthesis and Pharmacological Evaluation of Second Generation EZH2 Inhibitors with Long Residence Time. Med Chem Lett. 2020;11: $1205-1212$. 